\title{
Accredited Endoscopy Unit Program of Korea: Overview and Qualification
}

\author{
Jung-Wook Kim${ }^{1}$, Yu Kyung $\mathrm{Cho}^{2}$, Jin-Oh Kim${ }^{3}$, Jae-Young Jang ${ }^{1}$ and the Quality Management Committee of Korean Society of \\ Gastrointestinal Endoscopy
}

${ }^{1}$ Department of Internal Medicine, Kyunghee University College of Medicine, Seoul, ${ }^{2}$ Department of Internal Medicine, The Catholic University of Korea College of Medicine, Seoul, ${ }^{3}$ Institute for Digestive Research, Soonchunhyang University Seoul Hospital, Seoul, Korea

The Korean Society of Gastrointestinal Endoscopy introduced the Accredited Endoscopy Unit Program to enhance endoscopy unit quality through systematic quality management in 2012. It was gradually expanded from training hospitals to institutions with $100+$ beds, and the criteria for certification were applied according to the actual conditions of each institution. On the basis of the continuous communication with the institutions and feedback, the Accredited Endoscopy Unit Program certification criteria were revised in 2019 and introduced as follows: (1) the qualification criteria for endoscopy doctors and nurses; (2) facilities and equipment; (3) endoscopic examination process; (4) performance; (5) disinfection and infection control; and (6) endoscopic sedation. The assessment items consist of essential and recommended items. All essential items must be met for accreditation to be awarded. The assessment criteria for each evaluation area were revised as follows: (1) upgrading assessment criteria; (2) qualification of endoscopists and reinforcement of quality control education; (3) detailed standards for safety, disinfection, endoscopic sedation, and management instructions; and (4) presentation of new performance measurement of endoscopy and colonoscopy. Clin Endosc 2019;52:426-430

Key Words: Endoscopy; Quality; Unit; Accreditation

\section{INTRODUCTION}

The Korean Society of Gastrointestinal Endoscopy (KSGE) introduced the Accredited Endoscopy Unit Program to enhance the quality of endoscopy units through systematic quality management. Accredited endoscopy units are certified by KSGE to perform high-quality endoscopy practices. The important factors required to deliver the best endoscopy practice are as follows:

(1) Credentialing of endoscopy staff.

Received: August 24, 2019 Revised: August 30, 2019

Accepted: August 30, 2019

Correspondence: Yu Kyung Cho

Department of Internal Medicine, The Catholic University of Korea College of Medicine, Seoul St. Mary’s Hospital, 222 Banpo-daero, Seocho-gu, Seoul 06591, Korea

Tel: +82-2-2258-2064, Fax: +82-2-2258-2055, E-mail: ykcho@catholic.ac.kr ORCID: https://orcid.org/0000-0002-7297-6577

(c) This is an Open Access article distributed under the terms of the Creative Commons Attribution Non-Commercial License (http://creativecommons.org/ licenses/by-nc/3.0) which permits unrestricted non-commercial use, distribution, and reproduction in any medium, provided the original work is properly cited.
(2) Are the institutions following the guidelines for safety, endoscope disinfection, and endoscopic sedation as their unit policies as recommended by the KSGE?

(3) Do the endoscopy staff follow the standardized endoscopy procedures and assess their performance to meet the performance criteria?

(4) Continuous quality improvement activities

The system was introduced in 2012 at the level of an endoscopy specialist training hospital but was gradually expanded to institutions with having more than one hundred in-patient beds in 2014. It has now certified endoscopy units in more than 200 institutions, including more than 80 training hospitals. The criteria for certification must be revised on the basis of the actual conditions of each institution. On the basis of continuous communication with the site and feedback, the criteria for assessment of certification of the accredited endoscopy unit were revised in 2019 and will be introduced. 


\section{OVERVIEW OF EVALUATION AREA}

The six evaluation areas of the accredited endoscopy unit program are as follows:

(1) Qualification of endoscopists

(2) Facilities and equipment

(3) Process

(4) Performance

(5) Disinfection and infection control

(6) Endoscopic sedation

The assessment items are composed of mandatory and recommended items (Table 1). All mandatory items must be met for accreditation to be awarded. The program must be recertified every 3 years after the initial certification.

\section{ASSESSMENT CATEGORY: QUALIFICATION OF ENDOSCOPISTS (Table 2)}

\section{Mandatory items 9 items}

\section{Required personnel for endoscopy: 1 item}

1. Each endoscopy examination room must have at least one endoscopy physician and nursing staff. Endoscopy personnel must meet all certification assessment criteria.

\section{Qualification of endoscopists: 1 item}

1. More than $50 \%$ of endoscopy doctors should be KSGE board-certified endoscopy specialists. The remaining doctors should have experience with $>1,000$ cases of upper gastrointestinal endoscopy and 150 cases of colonoscopy. In case of a change in endoscopy physician at the time of re-certifica- tion evaluation, the criteria for assessment should be met for the initial certification.

Rationale: Upper gastrointestinal (GI) endoscopy and colonoscopy must be performed by licensed physicians to ensure diagnostic accuracy and patient safety. It is necessary to set appropriate qualification standards for physicians who perform upper GI endoscopy. Supportive data on the appropriate endoscopy treatment experience to gain competency or qualification are inadequate (Table 3). We can say that qualified endoscopy can be implemented only by an endoscopist who has a certain amount of experience at a training hospital with a qualified education supervisor. The KSGE recommends the performance of over 1,000 cases of upper GI endoscopy under the guidance of an instructor during the training period as a prerequisite for endoscopy specialist board certification by KSGE. ${ }^{1}$ The recommendations of the Japanese Society of Gastrointestinal Endoscopy ${ }^{2}$ and American Society of Gastrointestinal Endoscopy ${ }^{3}$ for ensuring competency are different from those of the KSGE. According to the quality guidelines for the national gastric cancer screening program in Korea, an endoscopy experience of at least 500 cases is strongly recommended for participation in the national gastric cancer screening program. ${ }^{4}$

Colonoscopy is an invasive procedure that can lead to complications, and differences in intubation success and diagnostic rates may result from practitioner competency. ${ }^{5}$ Some studies have reported differences in the detection rate of colorectal adenoma among practitioners and that the risk of overlooking colorectal cancer may vary depending on course content or majors of the training curriculum the practitioners completed. ${ }^{6,7}$ KSGE recommends the performance of over 150 cases of colonoscopy under the guidance of an instructor during the training period as a prerequisite for colonoscopists. ${ }^{1}$ To participate in the national colon cancer screening program, physicians should perform more than 150 colonoscopies in supervised training sessions for 1 year. ${ }^{8}$ If a physician has not received endoscopy training, an experience of performing a minimum of 300 successful colonoscopies is required to con-

Table 1. Number of Assessment Items for Each Evaluation Area

\begin{tabular}{lcc}
\hline Evaluation area & Mandatory items & Recommended items \\
\hline Qualification of endoscopists & 9 & 1 \\
Facilities and equipment & 16 & 7 \\
Process & 19 & 1 \\
Performance & 10 & 4 \\
Disinfection and infection control & 28 & 0 \\
Endoscopic sedation & 12 & 5 \\
\hline
\end{tabular}


duct a national colon cancer screening. ${ }^{8}$ In contrast, the Accredited Endoscopy Unit Program requires most physicians to undergo training for more than 1 year with a supervisor and endoscopy specialist board certified by the KSGE.

\section{Maintenance/continuing education of endoscopists (re-accreditation): 4 items}

\section{All endoscopy physicians should complete train-}

Table 2. Accreditation of Qualified Endoscopy Unit Assessment Items in Category: Qualification of Endoscopists

\begin{tabular}{|c|c|}
\hline Category & AQEU assessment items \\
\hline & Mandatory items (9 items) \\
\hline $\begin{array}{l}\text { Required personnel for } \\
\text { endoscopy }(1 \text { item })\end{array}$ & $\begin{array}{l}\text { 1. Each endoscopy examination room must have at least one endoscopy physician and nursing staff. Person- } \\
\text { nel for endoscopy must meet all certification assessment criteria. }\end{array}$ \\
\hline $\begin{array}{l}\text { Endoscopist qualifications } \\
\text { (1 item) }\end{array}$ & $\begin{array}{l}\text { 1. More than } 50 \% \text { of endoscopy doctors should be KSGE board-certified endoscopy specialists. The remain- } \\
\text { ing doctors should have experience with }>1,000 \text { cases of upper gastrointestinal endoscopy and } 150 \text { cases } \\
\text { of colonoscopy. In case of a change in endoscopy physician at the time of the re-certification evaluation, } \\
\text { the initial certification assessment criteria should be met. }\end{array}$ \\
\hline $\begin{array}{l}\text { Maintaining endoscopist } \\
\text { quality ( } 4 \text { items) }\end{array}$ & $\begin{array}{l}\text { 1. All endoscopy physicians should complete training courses related to the use of endoscopes with a score } \\
\text { of } \geq 18 \text { in the last } 3 \text { years. } \\
\text { 2. All endoscopy physicians should complete training courses related to endoscopy quality controls with a } \\
\text { score of } \geq 6 \text { in the last } 3 \text { years. } \\
\text { 3. During the } 3 \text {-year accreditation period, all upper gastrointestinal endoscopy physicians should perform at } \\
\text { least } 200 \text { upper gastroscopies per year or the corresponding number of upper gastrointestinal therapeutic } \\
\text { endoscopies. } \\
\text { 4. During the } 3 \text {-year accreditation period, all colonoscopists should perform at least } 100 \text { colonoscopies per } \\
\text { year or the equivalent number of therapeutic colonoscopies. }\end{array}$ \\
\hline $\begin{array}{l}\text { Education of endoscopy } \\
\text { nurses ( } 2 \text { items) }\end{array}$ & $\begin{array}{l}\text { 1. All endoscopy nursing staff must participate in regular maintenance training programs organized by the } \\
\text { Korean Society for Gastrointestinal Endoscopy and the Korean Nurse Society for Gastrointestinal Endos- } \\
\text { copy at least once every } 3 \text { years. } \\
\text { 2. New endoscopy nursing staff must complete the training program before participating in endoscopic ex- } \\
\text { aminations. }\end{array}$ \\
\hline \multirow[t]{2}{*}{$\begin{array}{l}\text { Education of new } \\
\text { endoscopy nurses (1 item) }\end{array}$} & 1. An education program should be provided when new endoscopy equipment and devices are introduced. \\
\hline & Recommended item (1 item) \\
\hline $\begin{array}{l}\text { Nursing staff in recovery } \\
\text { room ( } 1 \text { item) }\end{array}$ & 1. It is recommended that at least one nurse be present for each 10 beds in the recovery room. \\
\hline
\end{tabular}

AQEU, accreditation of qualified endoscopy unit; KSGE, Korean Society of Gastrointestinal Endoscopy.

Table 3. Comparison of Qualification Requirements (Certification or Minimum Number of Endoscopy Procedures)

\begin{tabular}{|c|c|}
\hline & Minimum number of upper gastrointestinal endoscopies required for qualification \\
\hline $\begin{array}{l}\text { Accredited Endoscopy Unit (certified by } \\
\text { KSGE) }\end{array}$ & $\begin{array}{l}\text { More than } 50 \% \text { of doctors should be endoscopy specialists. The remaining doctors } \\
\text { should have experience performing }>1,000 \text { cases of upper gastrointestinal endoscopy } \\
\text { and } 150 \text { cases of colonoscopy }\end{array}$ \\
\hline Board certified by $\mathrm{KSGE}^{1}$ & More than 1,000 cases of supervised endoscopy during the training period \\
\hline $\begin{array}{l}\text { Board certified by the Japanese Society of } \\
\text { Gastrointestinal Endoscopy }{ }^{2}\end{array}$ & $\begin{array}{l}\text { Extensive endoscopy experience (e.g., }>500 \text { upper gastrointestinal endoscopies, } 250 \\
\text { colonoscopies, and } 20 \text { endoscopy treatments) over the previous } 5 \text { years }\end{array}$ \\
\hline $\begin{array}{l}\text { Competency assessment by the American Soci- } \\
\text { ety of Gastrointestinal Endoscopy }\end{array}$ & $\begin{array}{l}\text { A minimum of } 130 \text { upper gastrointestinal endoscopy procedures, including } 25 \text { for the } \\
\text { treatment of nonvariceal hemorrhage and } 20 \text { for the treatment of variceal hemorrhage }\end{array}$ \\
\hline $\begin{array}{l}\text { Quality guidelines for the national gastric } \\
\text { cancer screening program (Korea National } \\
\text { Cancer Center) }\end{array}$ & More than 500 cases of supervised endoscopy \\
\hline
\end{tabular}

KSGE, Korean Society of Gastrointestinal Endoscopy. 
ing courses related to the use of endoscopes with a score of $\geq 18$ in the last 3 years.

2. All endoscopy physicians should complete training courses related to endoscopy quality controls with a score of $\geq 6$ in the last 3 years.

3. During the 3-year period of accreditation, all upper gastrointestinal endoscopy physicians should perform at least 200 upper gastroscopies per year or the corresponding number of upper gastrointestinal therapeutic endoscopies.

4. During the 3-year accreditation period, all colonoscopists should perform at least 100 colonoscopies per year or the equivalent number of therapeutic colonoscopies.

Rationale: From various studies conducted in Korea, it is well known that endoscopic examination proficiency and completion rate are correlated with endoscopist experience. Although the actual number of procedures performed does not necessary prove the endoscopist's skills, a minimum number of performed procedures is required for the assessment of proficiency and other performance indicators. The European Guidelines for Quality Assurance in Colorectal Cancer Screening and Diagnosis recommends that endoscopists participating in colorectal cancer screening programs should have experience performing at least 300 cases of colonoscopy per year, ${ }^{9}$ while the British Quality Assurance Guidelines for Colonoscopy requires that at least 100 procedures be performed each year to maintain colonoscopy proficiency. ${ }^{10}$ These represent minimum requirements for assessing endoscopist proficiency, and these guidelines recommend that the number of endoscopic procedures performed per year by each endoscopist be recorded. The standards for the number of endoscopy procedures performed per year recommended in various guidelines have a low quality of evidence and were proposed based on expert opinions. Accordingly, the standards being applied in Korea are also based on expert opinions, with the Quality Management Committee of the KSGE recommending 200 cases of upper GI endoscopy and 100 cases of colonoscopy per year.

\section{Education of endoscopy nurses: 2 items}

1. All endoscopy nursing staff must participate in regular maintenance training programs organized by the KSGE and the Korean Nurse Society for Gastrointestinal Endoscopy at least once every
3 years.

2. New endoscopy nursing staff must complete the training program before participating in endoscopic examinations.

Rationale: Endoscopy nursing personnel should have professional endoscopy knowledge and skills. Endoscopy nursing personnel should properly manage the instruments, equipment, and samples used in endoscopes and understand the basic knowledge of infection for its prevention and management. Therefore, a certain amount of pre-training time is required for endoscopy nursing personnel, who play an important role throughout the endoscopy procedure, and a program that is effectively configured for proper education is necessary. These training periods and programs should have established regulations for each institution, and the contents of the pre-training program should include understanding of endoscopy procedures and complications, nursing management for endoscopy examinees, infection control, and sedation management.

Education about new endoscopy devices: 1 item

1. An education program should be provided when new endoscopy equipment and devices are introduced.

Recommended item 1 item

Nursing staff in recovery room: 1 item

1. It is recommended that at least one nurse in the recovery room works on every 10 beds in the recovery room.

\section{CONCLUSIONS}

The six evaluation areas of the Accredited Endoscopy Unit Program are the qualification criteria for endoscopy doctors and nurses, facilities and equipment, endoscopy examination process, performance, disinfection and infection control, and endoscopic sedation. The assessment criteria for each evaluation area have been revised as follows: (1) upgrading assessment criteria; (2) qualification of endoscopists and reinforcement of quality control education; (3) detailed standards for safety, disinfection, endoscopic sedation, and management instructions are prepared; and (4) presentation of new perfor- 
mance measurement of endoscopy and colonoscopy. In this program, the credentialing of endoscopists requires that the endoscopist has specialized endoscopy training or performs a minimum number of procedures to demonstrate their competency. In addition, continuous education about endoscopy procedures and quality is required for unit staff.

\section{Conflicts of Interest}

The authors have no financial conflicts of interest.

\section{ORCID}

Jung-Wook Kim: https://orcid.org/0000-0002-5383-7934

Jin-Oh Kim: https://orcid.org/0000-0002-1773-8058

Jae-Young Jang: https://orcid.org/0000-0002-7930-1468

\section{REFERENCES}

1. Moon HS, Choi EK, Seo JH, et al. Education and training guidelines for the board of the Korean Society of Gastrointestinal Endoscopy. Clin Endosc 2017;50:345-356.

2. Hatanaka H, Yamamoto H, Lefor AK, Sugano K. Gastroenterology training in Japan. Dig Dis Sci 2016;61:1448-1450.
3. ASGE Standards of Practice Committee, Faulx AL, Lightdale JR, et al. Guidelines for privileging, credentialing, and proctoring to perform GI endoscopy. Gastrointest Endosc 2017;85:273-281.

4. Ministry of Health and Welfare, National Cancer Center. Quality guidelines of gastric cancer screening [Internet]. Seoul: The Korean Association of Internal Medicine; c2017 [updated 2018 Jan 31]. Available from: https://www.kaim.or.kr/guideline/file/cancer_file_03.pdf.

5. Rex DK, Bond JH, Winawer S, et al. Quality in the technical performance of colonoscopy and the continuous quality improvement process for colonoscopy: recommendations of the U.S. Multi-Society Task Force on Colorectal Cancer. Am J Gastroenterol 2002;97:1296-1308.

6. Rex DK, Kahi CJ, Levin B, et al. Guidelines for colonoscopy surveillance after cancer resection: a consensus update by the American Cancer Society and the US Multi-Society Task Force on Colorectal Cancer. Gastroenterology 2006;130:1865-1871.

7. Rex DK, Petrini JL, Baron TH, et al. Quality indicators for colonoscopy. Gastrointest Endosc 2006;63(4 Suppl):S16-S28.

8. Ministry of Health and Welfare, National Cancer Center. Quality guidelines of colorectal cancer screening [Internet]. Seoul: The Korean Association of Internal Medicine; c2017 [updated 2018 Jan 31]. Available from: https://www.kaim.or.kr/guideline/file/cancer_file_02.pdf.

9. Beg S, Ragunath K, Wyman A, et al. Quality standards in upper gastrointestinal endoscopy: a position statement of the British Society of Gastroenterology (BSG) and Association of Upper Gastrointestinal Surgeons of Great Britain and Ireland (AUGIS). Gut 2017;66:1886-1899.

10. Rees CJ, Thomas Gibson S, Rutter MD, et al. UK key performance indicators and quality assurance standards for colonoscopy. Gut 2016;65:1923-1929. 